\title{
COMPARISON OF EFFICACY AND SAFETY OF DEXMEDETOMIDINE AND PROPOFOL INFUSION FOR SEDATION DURING FIBREOPTIC NASOTRACHEAL INTUBATION
}

Nidhi Garg'1, Tejinderpal Kaur Grewal2 , Deepak Garg³

\section{HOW TO CITE THIS ARTICLE:}

Nidhi Garg, Tejinderpal Kaur Grewal, Deepak Garg. "Comparison of Efficacy and Safety of Dexmedetomidine and Propofol Infusion for Sedation during Fibreoptic Nasotracheal Intubation". Journal of Evolution of Medical and Dental Sciences 2014; Vol. 3, Issue 09, March 3; Page: 2140-2147, DOI: 10.14260/jemds/2014/2117

ABSTRACT: Fibreoptic intubation is a valuable modality for airway management. This study aimed to compare the efficacy and safety of dexmedetomidine and propofol infusion for sedation during fibreoptic nasotracheal intubation. Twenty patients of either sex aged between 18 to 60 years belonging to ASA I or ASA II grade were enrolled and randomly allocated into the dexmedetomidine group $(1.0 \mu \mathrm{g} / \mathrm{kg}$ infusion over $10 \mathrm{~min}$ followed by $0.5 \mu \mathrm{g} / \mathrm{kg} / \mathrm{hr}$. during fibreoptic nasotracheal intubation) $(\mathrm{n}=10)$ and the propofol group $(100 \mu \mathrm{g} / \mathrm{kg} / \mathrm{min}$ body weight over $10 \mathrm{~min}$ followed by $50 \mu \mathrm{g} / \mathrm{kg} / \mathrm{min}$ during fibreoptic nasotracheal intubation) $(\mathrm{n}=10)$. Intubating conditions and patient tolerance as graded by a scoring system were evaluated as primary outcomes. Intubation was successful in all patients. Satisfactory intubating conditions were found in both groups (10/10 in each group). In the evaluation of efficacy it was found that dexmedetomidine group had better patient tolerability according to 5 point fibreoptic intubation comfort score $(3.0 \pm 1.05$ and $1.8 \pm 1.03$ in propofol and dexmedetomidine group respectively $[\mathrm{p}<0.05])$. In the evaluation of safety it was found that in dexmedetomidine group better $\mathrm{Spo}_{2}$ is maintained during intubation $(\mathrm{p}<0.05)$, there was significant decrease in diastolic blood pressure in propofol group at the end of infusion $(\mathrm{p}<0.05)$ and there was significant decrease in pulse rate in dexmedetomidine group than propofol group at the end of infusion $(\mathrm{p}<0.05)$. Both drugs infusion are effective and safe to be used as sedative agent during fibreoptic nasotracheal intubation with same incidence of amnesia but better patient tolerance and $\mathrm{Spo}_{2}$ maintenance with dexmedetomidine.

KEYWORDS: Fibreoptic nasotracheal intubation, dexmedetomidine, propofol, infusion.

INTRODUCTION: Endotracheal intubation is the gold standard for maintenance of airway patency and gas flow, providing an open airway in anesthesiology. Tracheal intubation is the placement of a flexible plastic tube into the trachea to maintain a patent airway for ventilation. Endotracheal intubation can be done via mouth (orotracheal intubation) or via nose (nasotracheal intubation). Nasotracheal intubation can be done blindly, with the help of laryngoscope (with or without Magill's forceps) or fibreoptic nasotracheal intubation. Fibreoptic intubation can be performed awake under sedation with or without topical anesthesia or with muscle relaxant (suxamethonioum, Vecuronium, rocuronium, atracurium). For sedation, drugs that may be used are fentanyl/opioids, midazolam, propofol, dexmedetomidine, remifentanil. Propofol is a short-acting, intravenously administered hypnotic agent. Its uses include the induction and maintenance of general anesthesia, sedation for mechanically ventilated patients and procedural sedation. The currently available preparation is $1 \%$ propofol, $10 \%$ soyabean oil, $1.2 \%$ purified egg phospholipid (emulsifier), with $2.25 \%$ of glycerol as a tonicity-adjusting agent and sodium hydroxide to adjust the $\mathrm{pH}$. It acts through potentiation of GABA-A receptor activity, thereby slowing the calcium-closing time and also acting as a sodium 
channel blocker. Hypotension, oxyhemoglobin desaturation, apnea, and airway obstruction can occur, especially following a rapid bolus of Propofol. Dexmedetomidine is a highly selective, potent $\alpha 2$ agonist, with a short duration of action. It contains an imidazole ring. This new sedative has the ability to sedate and provide analgesia while maintaining patient arousability and respiratory function. The $\alpha 2 \mathrm{~A}$ receptors are located in the locus ceruleus and are responsible for the sedation, anxiolysis and sympatholysis mediated by G-protein inhibition of L-type calcium channels in the postsynaptic receptors. It has biphasic cardiovascular response as initially result in a transient increase of the blood pressure due to peripheral post-synaptic $\alpha 2 \mathrm{~B}$ stimulation with vasoconstriction ${ }^{1}$. Then there would be hypotension and bradycardia due to stimulation of pre-synaptic $\alpha 2 \mathrm{~A}$ with decreased norepinephrine ${ }^{2}$. This hypotension can be managed with atropine, ephedrine and volume infusion ${ }^{3}$. The respiratory depression has been reported to be much less than with other sedatives ${ }^{4}$. Atipamezole, $\alpha-2$ antagonist, is an effective antagonist for reversing psychomotor impairment following dexmedetomidine sedation ${ }^{5}$.

MATERIAL AND METHODS: The study was conducted in Government Medical College, Patiala. Total 20 Patients aged between 18-60 years and of ASA Grade I and II scheduled to undergo elective surgery were selected and randomly divided in two groups of 10 each.

\section{Exclusion criteria:}

- $\quad$ History of severe bradycardia and any type of A-V block in E.C.G

- Heart failure

- $\quad$ Liver cirrhosis

- Thrombocytopenia and Coagulopathy

- History of hypertension/diabetes mellitus/bronchial asthma/previous nasal surgery/nasal trauma/nasal polyp

METHOD: All patients received Inj.Glycopyrrolate $(0.2 \mathrm{mg}) \mathrm{i} / \mathrm{m} 30 \mathrm{~min}$ before the elective surgery. Group I patients received dexmedetomidine infusion $1 \mu \mathrm{g} / \mathrm{kg}$ body weight over $10 \mathrm{~min}$ followed by $0.5 \mu \mathrm{g} / \mathrm{kg} / \mathrm{hr}$. during fibreoptic nasotracheal intubation. The infusion was prepared by adding $2 \mathrm{ml}$ $(200 \mu \mathrm{g})$ of dexmedetomidine to $48 \mathrm{ml}$ of $0.9 \%$ saline solution making overall solution of $50 \mathrm{ml}$. Group II patients received propofol infusion $100 \mu \mathrm{g} / \mathrm{kg} / \mathrm{min}$ body weight over $10 \mathrm{~min}$ followed by $50 \mu \mathrm{g} / \mathrm{kg} / \mathrm{min}$ during fibreoptic nasotracheal intubation. The infusion was prepared by diluting adequate amount of propofol according to body weight in $0.9 \%$ saline solution making overall solution of $50 \mathrm{ml}$. Xylometazoline nasal drops were applied to both nostrils. Lidocaine jelly was applied to fiberscope and nostril. The nostril with least resistance was selected for nasal intubation. Nasopharyngeal airway (28 or 30 no.) introduced into nostril selected as dilator and for lubrication. Fibreoptic nasotracheal intubation was done in both groups of patients. After intubation, Isoflurane $1 \%$, Vec $(0.06-0.08 \mathrm{mg} / \mathrm{kg})$ was administered.

Clinically patients were monitored and following observation were recorded during the course of intubation: 


\section{Intraoperatively:}

1) Baseline, patient vitals (BP, Heart rate, $\mathrm{SpO}_{2}$ ) were documented. During infusion, patient vitals (BP, Heart rate, $\mathrm{SpO}_{2}$ ) were documented at 0, 5, 10 mins. During intubation, patient vitals (BP, heart rate, $\mathrm{SpO}_{2}$ ) were documented at 0, 3, 6 min.

2) Intubation scores -

a) Vocal cord movements (open=1, moving=2, closing=3, closed $=4$ )

b) Coughing (none $=1$, slight $=2$, moderate $=3$, severe $=4$ ),

c) Limb movement (none $=1$, slight $=2$, moderate $=3$, severe $=4$ )

3) Intubation time (time taken from inserting the fibreoptic scope to confirmation of nasotracheal intubation).

4) Patient tolerance assessed by:

a) 5 point fibreoptic intubation comfort score (no reaction=1, slight grimacing=2, heavy grimacing=3, verbal objection=4, defensive movement of head or hands=5).

b) 3 point score immediately after nasotracheal intubation (cooperative $=1$, restless $/ \mathrm{minimal}$ resistance $=2$, severe resistance $=3$ ).

5) Any complication or any drug used during procedure is noted.

ETHICS: While performing this study on human subjects, the procedures followed were in accordance with the ethical standards of the responsible committee on human experimentation (institutional or regional) and with the Helsinki Declaration of 1975 that was revised in 2000.

DISCUSSION AND RESULTS: During infusion in propofol group, mean baseline pulse rate was $78.4 \pm 5.15$ which at 5 min of infusion was $70.4 \pm 3.86$ and at 10 min was $65.8 \pm 2.74$. In comparison dexmedetomidine group had mean baseline pulse rate of $77.4 \pm 5.34$, at 5 min was $69 \pm 5.44$ and at 10 min was 60.8 \pm 1.69 . There was significant difference between two groups with decreased pulse rate in dexmedetomidine group at end of infusion. During intubation in propofol group, mean baseline pulse rate was $65.8 \pm 2.74$ which at 3 min was $64.8 \pm 2.7$ and at 6 min was $63 \pm 2.54$. In comparison dexmedetomidine group had mean baseline pulse rate of $64.4 \pm 4.3$ which at 3 mins and 6 mins was $63.6 \pm 3.86$ and $65.6 \pm 4.40$ respectively. There was no significant difference between two groups during intubation. Tsai et $\mathrm{al}^{6}$ in their study comparing dexmedetomidine and propofol target controlled infusion for sedation during fibreoptic nasotracheal intubation also found that heart rate was decreased significantly in dexmedetomidine group at the end of drug infusion. Similarly Venn $\mathrm{R}$ $\mathrm{M}^{7}$ while comparing dexmedetomidine and propofol sedation in ICU postoperative patients also found that heart rate was decreased significantly in dexmedetomidine group. In another study by Yusuke et $\mathrm{al}^{8}$ while comparing sedation of dexmedetomidine and propofol in healthy volunteers also found that heart rate decreased significantly in dexmedetomidine group. Bloor BC et $\mathrm{al}^{9}$ in their study of 37 healthy volunteers evaluated the hemodynamic effects of dexmedetomidine infusion also found that heart rate was decreased during dexmedetomidine infusion.

The Systolic blood pressure in our study shows no significant difference among two groups both during infusion and intubation. During infusion in propofol group, mean baseline systolic blood pressure, mean SBP at 5 mins and 10 mins were 126.8 $\pm 4.24,118.4 \pm 3.98$ and 110.8 with S.D 5.09 respectively. In dexmedetomidine group during infusion, mean baseline systolic blood pressure, mean SBP at 5 mins and 10 mins were $126.6 \pm 3.78,130.8 \pm 4.24$ and $118.0 \pm 5.89$. During intubation in 
propofol group, mean baseline systolic blood pressure was 110.8 \pm 5.09 which at 3 mins was 108.2 \pm 4.66 and at 6 mins was $108.6 \pm 4.05$. In dexmedetomidine group during intubation, mean baseline systolic blood pressure, mean SBP at 3 mins and 6 mins were $111.4 \pm 5.89,107.8 \pm 5.61$ and $110.0 \pm 6.73$ respectively. The diastolic blood pressure in our study however shows significant difference in two groups, by virtue of fall of DBP in dexmedetomidine group late in the procedure i.e. during intubation. During infusion in propofol group, mean baseline diastolic blood pressure, mean DBP at 5 mins and 10 mins were $81.2 \pm 3.79,74.4 \pm 3.46$ and $70.4 \pm 1.84$ respectively.

In dexmedetomidine group during infusion, mean baseline diastolic blood pressure, mean DBP at 5 mins and 10 mins were $79.2 \pm 4.83,79.2 \pm 4.13$ and $68.4 \pm 2.8$. During intubation in propofol group, mean baseline diastolic blood pressure was $70.4 \pm 1.84$ which at 3 mins was $69 \pm 4.03$ and at 6 mins was $64 \pm 3.80$. In dexmedetomidine group during intubation, mean baseline diastolic blood pressure, mean DBP at 3 mins and 6 mins were $68.4 \pm 2.80,66.4 \pm 4.09$ and $67.6 \pm 3.73$ respectively. Tsai et $\mathrm{al}^{6}$ in their study comparing dexmedetomidine and propofol target controlled infusion for sedation during fibreoptic nasotracheal intubation, found that there was no significant difference of mean blood pressure between two groups. Venn $\mathrm{R} \mathrm{M}^{7}$, also in their study comparing dexmedetomidine and propofol sedation in ICU postoperative patients had found no significant difference of systolic blood pressure between two groups.

Hall JE et al ${ }^{10}$ while evaluating sedation, analgesia, cognition and effect on cardiorespiratory function of dexmedetomidine infusion in 7 healthy young volunteers, didn't found any significant hemodynamic changes during dexmedetomidine infusion. Knolle $\mathrm{E}$ et al ${ }^{11}$ also found no significant hemodynamic instability while evaluating the target controlled infusion of propofol for fibreoptic intubation in 20 patients scheduled for outpatient oral surgery. Stuart A G et al ${ }^{12}$ evaluated dexmedetomidine infusion for sedation during fibreoptic intubation on 3 patients and they found that fibreoptic intubation was successful in all patients without any hemodynamic instability. Grant SA et al ${ }^{13}$ while evaluating the efficacy of dexmedetomidine infusion for sedation during fibreoptic intubation in 3 patients scheduled for cervical spine surgery, didn 't find any significant hemodynamic instability during the procedure. Bergese SD et al ${ }^{14}$ also found no significant hemodynamic instability while evaluating dexmedetomidine for sedation in difficult awake fibreoptic intubation in 4 patients.

During infusion of drug in propofol group, mean baseline $\mathrm{SpO}_{2}$ was $100 \pm 0$ which at 5 mins of infusion was $94.4 \pm 1.26$ and at 10 mins was $93.4 \pm 0.97$. In comparison dexmedetomidine group had mean $\mathrm{SpO}_{2}$ of $100 \pm 0$, at 5 min was $94.8 \pm 1.93$ and at 10 min was $94.2 \pm 1.13$. There was no significant difference between two groups when comparing $\mathrm{SpO}_{2}$ during infusion. During intubation in propofol group, mean baseline $\mathrm{SpO}_{2}$ was $93.4 \pm 0.97$ which at 3 min was $95.2 \pm 2.35$ and at 6 min was $94.2 \pm 2.20$. In comparison dexmedetomidine group had mean baseline $\mathrm{SpO}_{2}$ of $94.2 \pm 1.13$ which at 3 mins and 6 mins was $96.6 \pm 1.35$ and $99.4 \pm 0.97$ respectively.

There was significant difference between two groups during intubation with better $\mathrm{SpO}_{2}$ maintained in dexmedetomidine group. In our study there was one case of apnea occurring during infusion in propofol group, however patient $\mathrm{SpO}_{2}$ was maintained and patient recovered when fibreoptic bronchoscopy started without any supplemental oxygen. Tsai et al ${ }^{6}$ in their study also found that hypoxia occurred in 1 patient of propofol group with no significant difference between two groups in terms of $\mathrm{SpO}_{2}$. Hall JE et $\mathrm{al}^{7}$ in their study also concluded that evaluate that during dexmedetomidine infusion $\mathrm{SpO}_{2}$ was well maintained. Grant SA et al13 in their study to evaluate the efficacy of dexmedetomidine infusion for sedation during fibreoptic intubation in 3 patients 
scheduled for cervical spine surgery, found that dexmedetomidine did not causes respiratory distress in any patient.

The intubation Score when calculated and compared both in components and total showed no significant difference between propofol and dexmedetomidine groups. The mean vocal cord movement score in propofol group was $1.6 \pm 0.67$ and in dexmedetomidine group was, mean vocal cord movement score was $1.6 \pm 0.67$. While comparing mean coughing score, it was $2.0 \pm 0.67$ and $1.7 \pm 0.67$ in propofol and dexmedetomidine group respectively. The mean limb movement score in propofol group was $1.5 \pm 0.53$, as compare to $1.8 \pm 0.79$ in dexmedetomidine group. Comparing mean total intubation score in two groups it was $5.1 \pm 1.20$ and $5.1 \pm 1.29$ in propofol and dexmedetomidine group respectively. Tsai et $\mathrm{al}^{6}$ in their study found that dexmedetomidine group had more favorable intubation score for vocal cord movement than did propofol group but there was no significant difference of intubation score for coughing and limb movement among two groups.

While comparing the patient Tolerance in our study, by using 5 point fibreoptic intubation comfort score and 3 points score immediately after fibreoptic intubation, it was found that there was significant difference between two groups especially in intubation comfort score suggesting that dexmedetomidine had better patient tolerability. The mean 5 point fibreoptic intubation comfort score was $3.0 \pm 1.05$ and $1.8 \pm 1.03$ in propofol and dexmedetomidine group respectively. The mean 3 point score immediately after fibreoptic intubation in propofol was group was $1.5 \pm 0.53$ and that in dexmedetomidine group was $1.4 \pm 0.52$. The total patient tolerance was $4.5 \pm 1.17$ and $3.2 \pm 1.23$ in propofol and dexmedetomidine group respectively. Tsai et al 6 while comparing dexmedetomidine and propofol target controlled infusion for sedation during fibreoptic nasotracheal intubation also found that dexmedetomidine group had better patient tolerance than propofol group.

The total duration of intubation show no significant difference between two groups. In propofol group, mean total duration of intubation was $5.66 \pm 0.27$ and in dexmedetomidine group, mean total duration of intubation was $5.58 \pm 0.33$. Tsai et al ${ }^{6}$ also found that there was no significant difference between two groups in intubation time.

In propofol group, atropine was used in 2 patients for bradycardia. In dexmedetomidine group also, atropine was used in 2 patients for bradycardia. However there was no incidence of severe bradycardia $(\mathrm{HR}<40)$ in both group patients.

In propofol group, there were 10 patients having postoperative amnesia of fibrescopy and in dexmedetomidine group, there were 8 patients having postoperative amnesia of fibrescopy. Tsai et $\mathrm{al}^{6}$ also concluded that recall was higher in dexmedetomidine group compared to propofol group.

CONCLUSION: All the above mentioned fact suggest that both dexmedetomidine and propofol infusion provide satisfactory intubating conditions. Both drugs infusion are effective and safe to be used as sedative agent during fibreoptic nasotracheal intubation. Dexmedetomidine offers better patient tolerance during fibreoptic bronchoscopy and intubation with incidence of amnesia same in both groups.

\section{REFERENCES:}

1. Bloor BC, Ward DS, Belleville JP, Maze M. Effects of intravenous dexmedetomidine in humans. II. Hemodynamic changes. Anaesthesiology; 1992; 77:1134-1142. 
2. Aantaa R, Kanto J, Scheinin M, Kallio A, Scheinin H. Dexmedetomidine, an alpha 2-adrenoceptor agonist, reduces anaesthetic requirements for patients undergoing minor gynaecological surgery. Anaesthesiology; 1990; 73: 230-235.

3. Jalonen J, Hynynen M, Kuitunen A, Heikkila H, Perttila J, Salmenpera M et al. Dexmedetomidine as an anaesthetic adjunct in coronary artery bypass grafting. Anaesthesiology; 1997; 86: 331345.

4. Belleville JP, Ward DS, Bloor BC, Maze M. Effects of intravenous dexmedetomidine in humans. II. Hemodynamic changes. Anaesthesiology; 1992; 77: 1125-1133.

5. Aho M, Erkola O, Kallio A, Scheinin H, Korttila K. Comparison of dexmedetomidine and midazolam sedation and antagonism of dexmedetomidine with atipamezole. J Clin Anaesth.; 1993; 5(3): 194-203.

6. Tsai CJ, Chu KS, Chen TI, Lu DV, Wang HM, Lu IC. A comparison of the effectiveness of dexmedetomidine versus propofol target-controlled infusion for sedation during fibreoptic nasotracheal intubation. Anaesthesia. 2010; 65: 254-259.

7. Venn RM, Grounds RM. Comparison between dexmedetomidine and propofol for sedation in the intensive care unit. British Journal of Anaesthesia. 2001; 87(5): 684-690.

8. Yusube K, Raghavendra G, Stefan R, Edward J M, Daniel I, Alparslan T. The correlation between Bispectral Index and Observational sedation scale in volunteers sedated with Dexmedetomidine and Propofol. Anesth Analog. 2009; 109: 1811-1815.

9. Bloor BC, Ward DS, Belleville J P, Maze M. Effects of intravenous dexmedetomidine in humans: Hemodynamic changes. Anesthesiology. 1992; 77(6): 1134-1142.

10. Hall JE, Uhrich TD, Barney JA, Arian SR, Ebert TJ. Sedative, amnestic and analgesic properties of small dose dexmedetomidine infusions. Anesth Analog. 2000; 90(3): 699-705.

11. Knolle E, Oehmke MJ, Gustorff B, Hellwagner K, Kress HG. Target-controlled infusion of propofol for fibreoptic intubation. European Journal of Anaesthesiology. 2005; 20(7): 565 -569.

12. Stuart AG, Dara S B, David BM, David G, Gavin M. Dexmedetomidine infusion for sedation during fibreoptic intubation: a report of three cases. Journal of clinical anesthesia. 2003; 16(2): 124126.

13. Grant SA, Breslin DS, Macleod DB, Gleason D, Martin G. Dexmedetomidine infusion for sedation during fibreoptic intubation: a report of three cases. J Clin Anesth. 2004; 16(2): 124-126.

14. Bergese SD, Candiotti KA, Bokesch PM, Zura A, Wisemandle W, Bekker AY. A Phase IIIb, randomized, double-blind, placebo-controlled, multicenter study evaluating the safety and efficacy of dexmedetomidine for sedation during awake fibreoptic intubation. Am J Ther. 2010; 17(6): 586-95. 


\begin{tabular}{|l|l|c|c|c|c|c|c|}
\hline \multicolumn{2}{|c|}{} & \multicolumn{3}{c|}{$\begin{array}{c}\text { During infusion } \\
\text { (in minutes) }\end{array}$} & \multicolumn{3}{c|}{$\begin{array}{c}\text { During intubation } \\
\text { (in minutes) }\end{array}$} \\
\hline Vitals & Groups & 0 & 5 & 10 & 0 & 3 & 6 \\
\hline $\begin{array}{l}\text { Pulse rate } \\
\text { (in bpm) }\end{array}$ & Propofol & $78.4+-5.15$ & $70.4+-3.86$ & $65.8+-2.74$ & $65.8+-2.74$ & $64.8+-2.7$ & $63+-2.54$ \\
\cline { 2 - 8 } & Dexmedetomidine & $77.4+-5.34$ & $69+-5.44$ & $60.8+-1.69$ & $64.4+-4.3$ & $63.6+-3.86$ & $65.6+-4.40$ \\
\hline $\begin{array}{l}\text { Systolic } \\
\text { blood pressure } \\
\text { (in mm of Hg) }\end{array}$ & Propofol & $126.8 \pm 4.24$ & $118.4 \pm 3.98$ & $110.8 \pm 5.09$ & $110.8 \pm 5.09$ & $108.2 \pm 4.66$ & $108.6 \pm 4.05$ \\
\cline { 2 - 8 } & Dexmedetomidine & $126.6 \pm 3.78$ & $130.8 \pm 4.24$ & $118 \pm 5.89$ & $111.4 \pm 5.89$ & $107.8 \pm 5.61$ & $110 \pm 6.73$ \\
\hline $\begin{array}{l}\text { Diastolic blood pressure } \\
\text { (in mm of Hg) }\end{array}$ & Propofol & $81.2 \pm 3.79$ & $74.4 \pm 3.46$ & $70.4 \pm 1.84$ & $70.4 \pm 1.84$ & $69 \pm 4.03$ & $64 \pm 3.80$ \\
\cline { 2 - 8 } & Dexmedetomidine & $79.2 \pm 4.83$ & $79.2 \pm 4.13$ & $68.4 \pm 2.8$ & $68.4 \pm 2.80$ & $66.4 \pm 4.09$ & $67.6 \pm 3.73$ \\
\hline \multirow{2}{*}{$\begin{array}{l}\text { Spo } 2 \\
\text { nyyyyyyyy}\end{array}$} & Propofol & $100 \pm 0$ & $94.4 \pm 1.26$ & $93.4 \pm 0.97$ & $93.4 \pm 0.97$ & $95.2 \pm 2.35$ & $94.2 \pm 2.20$ \\
\cline { 2 - 8 } & Dexmedetomidine & $100 \pm 0$ & $94.8 \pm 1.93$ & $94.2 \pm 1.13$ & $94.2 \pm 1.13$ & $96.6 \pm 1.35$ & $99.4 \pm 0.97$ \\
\hline
\end{tabular}

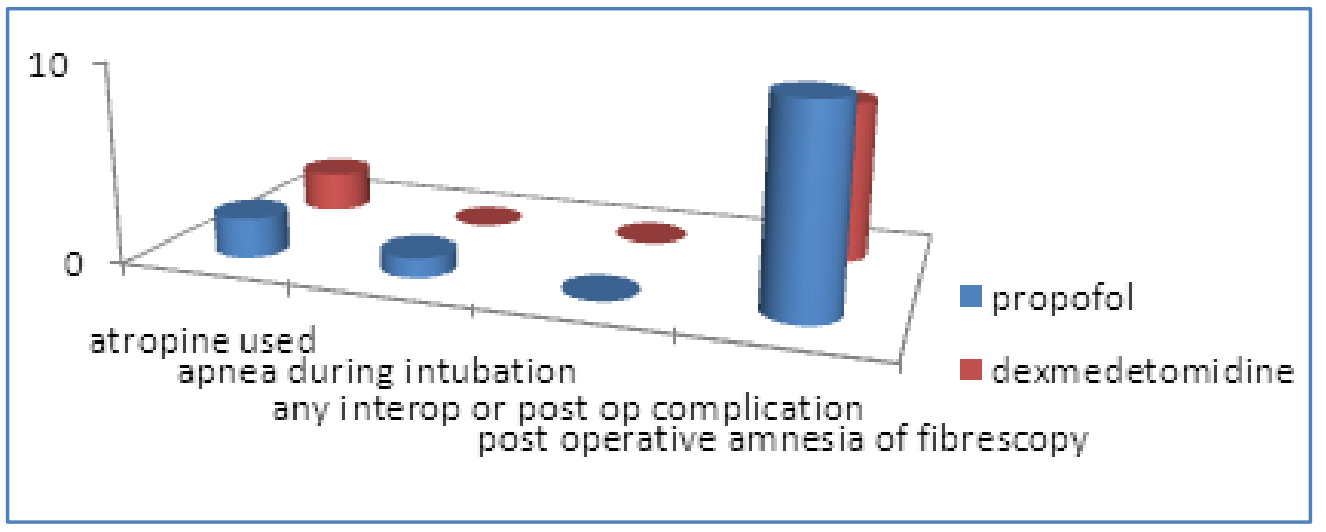

Fig. 1: Whether any drug used, any complication during procedure or any post operative complication and amnesia

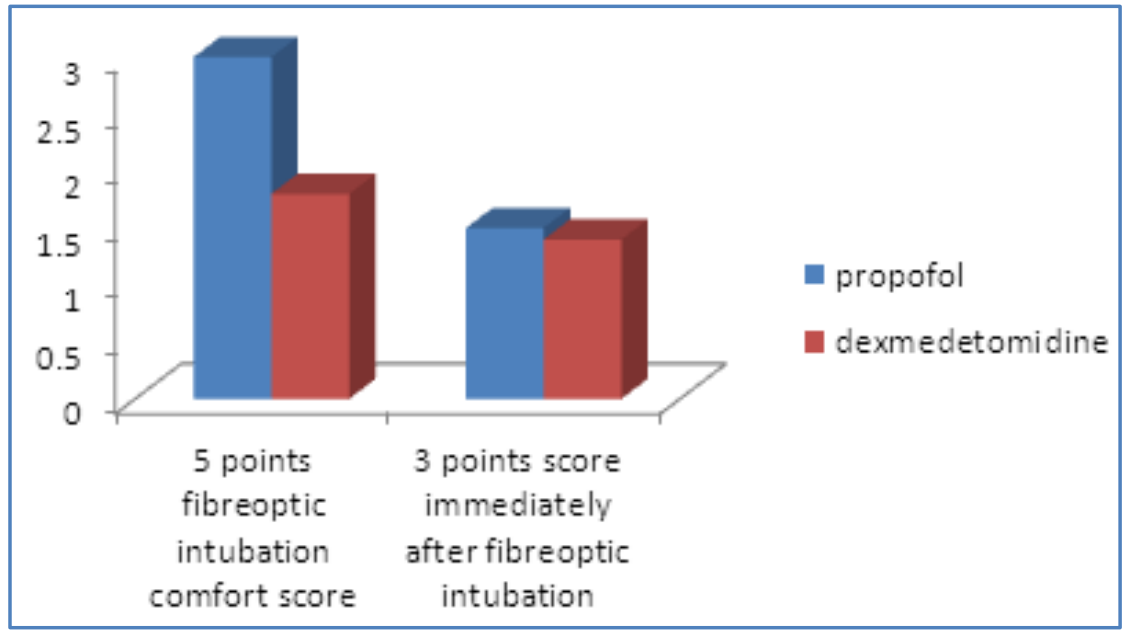

Fig. 2: Patient tolerance 


\section{ORIGINAL ARTICLE}

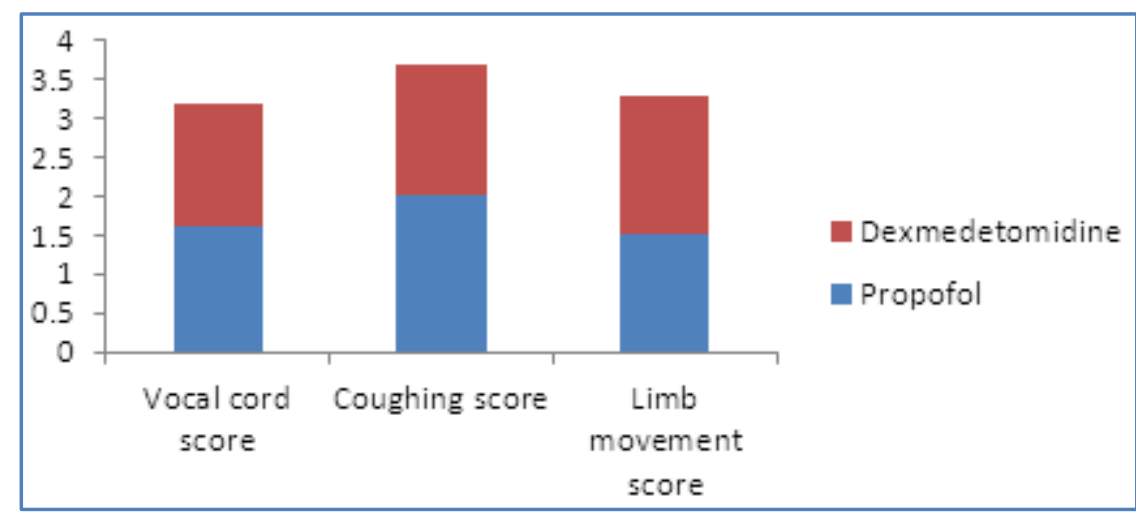

Fig. 3: Intubation score

\section{AUTHORS:}

1. Nidhi Garg

2. Tejinderpal Kaur Grewal

3. Deepak Garg

\section{PARTICULARS OF CONTRIBUTORS:}

1. Senior Resident, Department of Anaesthesiology, Sri Guru Ramdas Institute of Medical Sciences and Research, Amritsar, Punjab

2. Associate Professor, Department of Anaesthesiology, Government Medical College, Patiala, Punjab.

3. Senior Resident, Department of Medicine, Sri Guru Ramdas Institute of Medical Sciences and Research, Amritsar, Punjab

Date of Submission: 07/02/2014. Date of Peer Review: 08/02/2014. Date of Acceptance: 14/02/2014. Date of Publishing: 25/02/2014. 